\title{
Physical Fitness for Elderly of a University Project Participants, Practitioners of Weight and Welcoming House Residents
}

\author{
Paola Ferreira dos Santos, Lidiane Requia Alli Feldmann*, Rebecca Moreira Franco, Lucimara Pereira, Antonio \\ Eduardo Moura and Lauro Antonio dos Santos Mattos
}

Department of Physical Education, Lutheran University of Brazil, Brazil

*Corresponding author: Lidiane R Alli Feldmann, Department of Anxiety andDepression, Lutheran Universityof Brazil, Rua Santo André, 60apto 1103, Canoas RS,Brazil

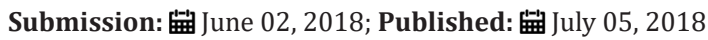

\begin{abstract}
The strengthening of the elements of physical fitness through physical activity is extremely important for the elderly and are directly associated with independence and autonomy in their day-to-day. This study aimed to evaluate physical fitness in three different senior groups, namely elderly participants of a university extension project with physical activity, body builders in conventional and residents academies shelters without physical activity. Were invited, voluntarily, 110 elderly, divided into G1, G2 and G3, respectively, through a battery of fitness tests adapted to the elderly, with assessments of strength and flexibility lower and upper limbs, speed, agility and balance, flexibility the upper limbs and aerobic resistance were also evaluated body mass index (BMI), waist-hip ratio, systolic blood pressure and diastolic blood pressure. The results show that in all the variables G3 presented rated below the other groups, except BMI compared to G1 and G2, and testing to achieve the back, compared to the G1, thus the G3 was rated risk of loss functional mobility in most tests. The conclusion is the need for the inclusion of older people in physical activity for the maintenance and improvement of physical fitness, thus favoring the quality of life in the aging process.
\end{abstract}

Keywords:Elderly; Physical fitness; Physical activity

\section{Introduction}

Aging is a dynamic and progressive process, in which both morphological and functional and biochemical can interfere with an individual's ability to adapt to the social environment in which he lives, making it more vulnerable to injuries and diseases, thus compromising their quality of life [1]. It is predicted that in Brazil the population over 60 years of age is approximately $11 \%$ of the population by 2020 , and $26.7 \%$ of the total in 2060 [2]. And to have a healthy aging, Maciel [3], it mentions that the adoption of an active lifestyle provides many health benefits, since it is considered as an important component for improving the quality of life and functional independence of the elderly. Physical activity acts as an important tool, maintaining and/or improving physical fitness levels with advancing age, thus reducing functional limitations [4]. Strengthening of physical fitness elements is extremely important for the elderly and are directly associated with independence and autonomy in their day-to-day [5].

According to Silveira [6] physical fitness can be divided into biological attributes such as strength and muscular endurance, flexibility, aerobic capacity, weight control, which offer some protection to the appearance of organic disorders caused by sedentary lifestyle or related to the performance, which involves a number of related components to sports or work performance, such as agility, balance, coordination, power and speed of displacement and muscle reaction. Exercise can produce a profound improvement of essential functions for the physical fitness of the elderly. Weight training, for example, is an important tool for the improvement of physical fitness, independence and quality of life in this population. Increases in strength and muscle power, important for maintaining independence and reducing falls among the elderly, can be observed after a few weeks of weight training [7]. Already the group carried out systematic physical exercises favors the accession of the elderly bringing health benefits and expanding both the biological aspects as psychosocial [8].

A sedentary lifestyle can accelerate the aging process through limitations of functional fitness [9]. So for Coelho et al. [8] is of great importance to preserve physical through exercise, it is they who dictate the pace in relation to the activities of everyday life, and this is more evident in ages where the decline of body functionality is more evident, making it difficult to performing simple activities and compromising the quality of life. Given the importance of physical exercise for the maintenance and improvement of the components of physical fitness of the elderly, this study aimed to evaluate the fitness of three groups of elderly, they were divided into elderly 
participants of an extension project university with physical activity, body builders and residents in conventional gyms shelters without physical activity.

\section{Materials and Methods}

\section{Sample}

For the study were invited on a voluntary basis, 110 elderly patients aged 60 years, of both sexes in the city of Canoas and surroundings. Participants were divided into three groups: the G1 elderly participants of an extension project of a university, the G2 body builders, both with 6 months minimum of physical exercise and the elderly residents G3 houses host (home) without physical exercise.

\section{Data collection procedure}

Physical fitness was assessed through a battery of tests Rikli \& Jones [10]aerobic endurance, flexibility, and agility/balance. Body mass index was also assessed as an estimate of body composition. The sample comprised 7,183 participants from 267 sites in 21 states. Summary data (M, SD, and percentiles With power ratings of the lower limbs (test stand and sit chair), upper limb strength (forearm flexion), flexibility of the lower limbs (test sit and reach), speed, agility and balance (walking test 2, 44 meters and return to sit), flexibility of upper limbs (up the back) and aerobic endurance (walking test 6 minutes). They were also evaluated in waist, abdomen and hip for calculating the waist hip ratio (WHR), as well as height and weight to calculate body mass index (BMI) and also checking the systolic blood pressure (SBP) and diastolic blood pressure (DBP), and the elderly hypertensive blood pressure kept controlled (PA) by drug treatment. Conducting the tests occurred in random days between the groups running in days participants of G1 and G2 had not done exercise, so not that there was interference in outcomes. It began with all to stand for 5 minutes to check the PA with a pulse digital apparatus brand Citizen CH-602B. Soon after checking the weight with a digital scale precision Plenna 100gr, height with a stadiometer and circumference of waist, abdomen and hip with a tape measure. They were initiated then the physical tests and the last to be done was the 6 min test. The results were recorded on a card, individual per participant and typed in Excel 2013 program.

\section{Statistical Analysis}

To compare the mean of the variables BMI, WHR and arm bending tests and 6 minutes walk used the ANOVA and to detect differences between groups, we used statistical Bonferroni post hoc test. Already in the variables of the test sitting and standing, sit and reach, reach back, agility and balance, SBP and DBP for failing to submit normal distribution, we used the statistical test nonparametric Kruskal Wallis test to compare the averages of the groups.

\section{Ethical Aspects}

All participants signed the Term of Free and Informed (IC), being informed about the procedures for research, accepting voluntarily participate in the study.

\section{Result}

The Table 1 below shows the results of the battery of fitness tests Rikli \& Jones [10] for elderly, presenting the results in groups, number of participants in each group, mean, standard deviation, ANOVA test results and level of significance. Evaluating the results, with respect to BMI groups showed significant difference $(\mathrm{p}<0.05)$, compared to only G2 G3. In relation to age and WHR G1, G2 and G3 showed significant difference $(\mathrm{p}=0.000)$ and the arm flexion test $(p=0.001)$ and 6-minute walk, though this significance in relation to G1 and G2 was ( $\mathrm{p}=0.006)$ and between G3 and the other groups was $(\mathrm{p}=0.000)$. The tests of sitting and standing, sit and reach, reach back, agility and balance, SBP and DBP did not show normal distribution. BMI remained normal classification in the G3, but the G1 and G2 presented classification of overweight, while WHR presented in G1, G2 and G3 the high, moderate and very high ratings respectively [11].

Table 1: Descriptive and inferential statistical sample.

\begin{tabular}{|c|c|c|c|c|c|c|}
\hline Test & Group & $\mathbf{N}$ & Average & DP & $\mathbf{F}$ & Sig \\
\hline \multirow{3}{*}{ Age } & 1 & 46 & 70.52 & 6.15 & \multirow{3}{*}{22.68} & \multirow{3}{*}{$0,000^{*}$} \\
\hline & 2 & 33 & 65.7 & 6.99 & & \\
\hline & 3 & 31 & 77.29 & 8.5 & & \\
\hline \multirow{3}{*}{ BMI } & 1 & 46 & 28.88 & 4.47 & \multirow{3}{*}{10.79} & \multirow{3}{*}{$0,000^{*}$} \\
\hline & 2 & 33 & 25.77 & 3.9 & & \\
\hline & 3 & 31 & 24.72 & 4.36 & & \\
\hline \multirow{3}{*}{ WHR } & 1 & 46 & 0.87 & 0.68 & \multirow{3}{*}{34.526} & \multirow{3}{*}{$0,000^{*}$} \\
\hline & 2 & 33 & 0.8 & 0.67 & & \\
\hline & 3 & 31 & 0.95 & 0.71 & & \\
\hline \multirow{3}{*}{ Bending arm } & 1 & 44 & 16.06 & 3.51 & \multirow{3}{*}{117.747} & \multirow{3}{*}{$0,000^{*}$} \\
\hline & 2 & 33 & 19.03 & 3.67 & & \\
\hline & 3 & 28 & 6.25 & 2.73 & & \\
\hline
\end{tabular}




\begin{tabular}{|c|c|c|c|c|c|c|}
\hline \multirow{3}{*}{ Test 6 Minutes } & 1 & 46 & 564.97 & 98.45 & \multirow{3}{*}{89.088} & \multirow{3}{*}{$0,000^{*}$} \\
\hline & 2 & 33 & 488.06 & 99.55 & & \\
\hline & 3 & 31 & 217.84 & 121.61 & & \\
\hline \multirow{3}{*}{ Sitting and standing } & 1 & 46 & 13.15 & 2.49 & \multirow{3}{*}{ - } & \multirow{3}{*}{$0,000^{*}$} \\
\hline & 2 & 33 & 14.69 & 3.68 & & \\
\hline & 3 & 31 & 7.7 & 3.42 & & \\
\hline \multirow{3}{*}{ Sit and Reach } & 1 & 46 & -1.48 & 0.97 & \multirow{3}{*}{-} & \multirow{3}{*}{$0.001^{*}$} \\
\hline & 2 & 33 & 3.45 & 1.39 & & \\
\hline & 3 & 31 & -6.54 & 2.63 & & \\
\hline \multirow{3}{*}{ Achieving Back } & 1 & 46 & -8.82 & 6.94 & \multirow{3}{*}{ - } & \multirow{3}{*}{$0,000^{*}$} \\
\hline & 2 & 33 & 1.65 & 5.25 & & \\
\hline & 3 & 29 & -6.54 & 22.51 & & \\
\hline \multirow{3}{*}{ Agility and balance } & 1 & 45 & 6.68 & 1.57 & \multirow{3}{*}{ - } & \multirow{3}{*}{$0,000^{*}$} \\
\hline & 2 & 33 & 7.06 & 3.86 & & \\
\hline & 3 & 31 & 29.81 & 24,40 & & \\
\hline \multirow{3}{*}{ PAS } & 1 & 46 & 120.3 & 2.57 & \multirow{3}{*}{-} & \multirow{3}{*}{0.276} \\
\hline & 2 & 33 & 124.84 & 1.6 & & \\
\hline & 3 & 31 & 127.56 & 2.79 & & \\
\hline \multirow{3}{*}{ PAD } & 1 & 46 & 73.04 & 11.71 & \multirow{3}{*}{-} & \multirow{3}{*}{$0.004^{*}$} \\
\hline & 2 & 33 & 79.9 & 7.68 & & \\
\hline & 3 & 31 & 80.32 & 11.65 & & \\
\hline
\end{tabular}

Comparing the results of fitness tests isolation between G1, G2 and G3 from the classification Rikli \& Jones [11] in six minutes walk test, sit and stand, sit and reach and foot agility and balance, G1 and G2 maintained normal classification as G3 presented risk of loss of functional mobility. Since the arm bending test showed normal rating G1, G2 was above average risk of G3 and functional loss of mobility test and reach the back, G1 presented below the average while G2 and G3 were considered normal. Finally, the classification of SBP/DBP and remained normal in G1, G2 and G3 [12]. The above results show that in all the variables G3 presented rated below the other groups, except BMI compared to G1 and G2, and testing to achieve the back, compared to the G1, thus the G3 was rated risk loss of functional mobility in most tests. Already the highest score was evident in G2, except the variables BMI, SBP/DBP and six minutes walk test, the latter with better ranking G1 (Table 1).

\section{Discussion}

Aging alone leads to loss of functional skills and cognitive functioning [5]. Aggravating this process when you do not have the habit of regular physical exercise, as shown by the results presented above, where G1 and G2 (of exercise practitioners), showed better results in most physical fitness tests when compared to G3 ( non-practicing). It was possible to assess that in relation to BMI, G3 remained within normal limits, even though the sedentary group as G1 and G2 were overweight and can be explained by the fact that the power was not controlled during the study and we do not know the diet adopted by the elderly home. SBP and DBP remained in the normal rating G1, G2 and G3, which we believe is due to the blood pressure control in hypertensive elderly, by the use of antihypertensive drugs in the three groups.

Have physical fitness showed better rating in all tests in G1 and G2 compared to G3 except the test to reach the back, only G3 compared to G1. This disagrees with the study Fidelis et al. [13] 74 old, divided into two groups of 37 individuals each, and practitioners and not physical activity practitioners in which significant differences between groups with respect to flexibility, demonstrating the efficacy of supervised exercise training with respect to improvement of flexibility. On the difference in levels of fitness of G1 and G2 was compared with G3, our findings corroborate the literature review Lamb et al. [14] where it was possible to realize the benefits provided by physical activity in relation to maintaining the health and functional capacity of the elderly, allowing deduce that a sedentary lifestyle can accelerate the decrease of functional capacity, leading to dependence on the performance of everyday activities.

Still on the benefits of physical activity, comparing practitioners and non-practitioners in the elderly population, the study of Borges [15] With 24 elderly practitioners of physical activities and 24 sedentary elderly, indicated that practitioners had good levels of autonomy to carry out their daily activities while sedentary were more difficult and even dependency. As in this study, the data presented above show, that no physical exercise brought the G3 risk loss of functional capacity, worsening their quality of life and 
independence. The quality of life of elderly residents of shelters, may also be associated with other factors, according to the study Dágios et al. [16] which showed lower degree of satisfaction in quality of life compared to non-institutionalized elderly in the four domains (physical, psychological, social relationships and environment) of the WHOQOL-BREF, and in the six domains (sensory function, autonomy, past activities, gifts and future, social participation, death and dying and intimacy) of the WHOQOL-OLD.

Lamb et al. [14] evaluating the quality of life of elderly residents of shelters through the WHOQOL-OLD questionnaire, found that the average score of $52.9 \%$, corresponding to a perception neither satisfactory nor unsatisfactory quality of life. The elderly living in long-stay institutions have reduced visual, cognitive and physical abilities, compromising the autonomy and independence, which may be associated with low quality of life of seniors. In addition, physical inactivity helps the onset of sarcopenia, a problem that occurs due to loss of muscle mass by the death of motor units and can be avoided through strength training, and aerobic exercise also has positive effects on the reduction of muscle loss during aging [17]. It was observed in Ritti Study Days [7] increase in muscle strength after a few weeks of weight training with seniors, and thus can help not only the independence, but also in reducing the incidence of falls, joint event with the muscle wasting process (sarcopenia).

And even among institutionalized elderly, a study by Ribeiro et al. [18] With 144 elderly residents of shelters offering its residents exercise programs in Oporto (Portugal), showed that elderly trained showed improved functional mobility and balance with consequent reduction of the risk of falling that untrained elderly. From the results presented by the G1, showing the relationship of the practice of physical activities offered by the project with the maintenance of the elements of physical fitness, the study of Santos [19] with 141 elderly patients at a university extension program in Florianópolis-SC also showed that participation in different leisure activities offered by the program is associated with good perception of quality of life of the investigated elderly because all domains and facets evaluation showed average above 60 . Finally, the results of this study and studies above show the benefits of physical activity on physical fitness and consequently the quality of life of seniors (Table 2). according to Lamb [14] it is evident the importance of physical activity in the delay of aging declines, it is necessary to create strategies for the participation of older people in physical activity groups, contributing to improving the quality of life and independence of older people [15-19].

Table 2: You are invited to participate in the research project identified above. The document below contains all the necessary information about the research we are doing. Your cooperation in this study will be of great importance to us, but to give up at any time, this will not cause any harm to you.

\section{Research Project Identification}

Project Title: Comparative Analysis of Physical Fitness of Elderly Participants of a University Project, Body Builders and Residents in Shelters

\begin{tabular}{|l|c|c|c|c|c|c|}
\hline \multicolumn{3}{|c|}{ Knowledge Area: Health } & Number of participants & \multicolumn{3}{c|}{ In the center } \\
\hline Course: Physical Education & International & Foreign cooperation & Yes & No \\
\hline Multicenter project & Yes & No & National & Sponsor results \\
\hline \multicolumn{7}{|c|}{ Institution which will be held } \\
\hline \multicolumn{7}{|c|}{ Name of researchers and collaborators } \\
\hline
\end{tabular}

\section{Conclusion}

Table 3: I the subject of research, the undersigned after receiving information and clarification on the research project identified above

\begin{tabular}{|l|c|c|c|c|}
\hline \multicolumn{4}{|c|}{ Identification of Subject Search } \\
\hline \multicolumn{3}{|c|}{ Name: } & Birth date: & Sex: \\
\hline \multicolumn{3}{|c|}{ Nationality: } & Marital status: & Profession: \\
\hline RG: & CPF / MF: & Telephone: & Email: \\
\hline \multicolumn{3}{|c|}{ Address: } \\
\hline
\end{tabular}

It was observed from the results presented above, the groups practicing physical activities were significantly higher in the results of fitness tests compared to the group of sedentary individuals. Especially in shelters, it is necessary the implementation of physical activity programs for these elderly people do not become dependent, thus losing their autonomy. It follows from this study and other studies presented, the need for the inclusion of older people in physical activity supervised the maintenance and improvement of physical fitness and functional capacity, thus favoring the quality of life and independence in the process aging (Table 3 ).

\section{Annex 1}

\section{The rationale and objectives for this research}

This research aims to assess the physical fitness of institutionalized elderly, bodybuilders and living group of participants.

\section{The purpose of my participation}

Their participation will be crucial for this study in helping us figure out which of the physical fitness groups shows better results as the physical activity levels of each group.

\section{The procedure for data collection}

The test will be performed: Battery physical fitness testing Rikli \& Jones [10]. 


\section{The use, storage and disposal of samples}

The information collected will be used for purposes of academic studies, they will only be used in this research may separately or compose other academic studies related matters. After the use of the data material will be disposed of, ensuring the confidentiality of information (Table 4).

Table 4: I agree of his own free will to participate as a volunteer and I am aware.

\begin{tabular}{|l|c|c|}
\hline \multicolumn{3}{|c|}{ Identification of the Principal Investigator } \\
\hline \multicolumn{2}{|c|}{ Name: } & Telephone: \\
\hline Profession: & Registrationon Council number: & Email: \\
\hline \multicolumn{2}{|c|}{ Address: } \\
\hline
\end{tabular}

\section{of the discomforts and risks}

In case of any discomfort or discontent communicate the assessor for the test to be stopped.

\section{Benefits}

You can meet your fitness rating, and contribute to assessments of physical activity programs of the projects so that they can be improved.

\section{The exemption and reimbursement of expenses}

My participation is free of cost and will not receive compensation because they will not have expenses in testing.

\section{The freedom to refuse, withdraw or withdraw my consent}

I have the freedom to refuse, withdraw or discontinue this research collaboration at the time you want, without any explanation. My withdrawal will not cause any damage to my health or physical well being. Will not interfere with the study.

\section{Da guaranteed confidentiality and privacy}

The results obtained during this study will be kept confidential, but I agree that they are published in scientific journals, since my personal data are not mentioned.

\section{The clarification assurance and information at any time}

I have the assurance to know and get information at any time, procedures and methods used in this study as well as the results of this research. Therefore, you can consult the responsible researcher Paola Ferreira dos Santos. For questions not cleared properly by the (s) researcher (s) of disagreement with the procedures, or ethical irregularities still be able to contact the Ethics Committee of the ULBRA Canoas (RS), at Rua Ragamuffin, 8001-Building 14-Room 224, Barrio San Jose, CEP 92425-900-phone (51) 3477-9217, Email: comitedeetica@ulbra.br

\section{References}

1. Souza RF, Enfermeira ST, Brêtas ACP (2007) Envelhecimento e família a new perspective for or care of sick people. Rev Bras Enferm [Internet] 60(3): 263-267.
2. IBGE (2013) Censo 2010. Atlas censo Demogr 35:

3. Maciel M (2010) Atividade física e funcionalidade do idoso. Motriz 16(4): 1024-1032.

4. Petreça DR, Hauser E, Mazo, GZ, Benedetti TB (2015) Influência da ginástica na aptidão física funcional de mulheres Influence of gym in physical functional skills of women. R bras Ci e Mov 23(2): 137-147.

5. Vila CP, Silva MEM, Simas JPN, Guimarães AC, Parcias SR (2013) Aptidão física funcional e nível de atenção em idosas praticantes de exercício físico. Rev Bras Geriatr e Gerontol 16(2): 355-364.

6. Silveira SC, Faro ACM (2008) contribuição da reabilitação na saúde e na qualidade de vida do idoso no brasil: reflexões para a assistência multidisciplinar. Estud Interdiscip Envelhec 13(1): 55-62.

7. Rittidias R (2006) Strength training benefits on the physical fitness of elderly individuals. Acta Fisiatr 13(2): 90-95.

8. Coelho FGM, Quadros AC, Gobbi S (2008) Efeitos do treinamento de dança no nível de aptidão funcional de mulheres de 50 a 80 anos. Rev da Educ Física/UEM 19(3): 445-451.

9. Oliveira VM, Brasil MR, Cavazzotto TG, Ferreira SA, Queiroga MR (2016) Aptidão funcional de mulheres de meia-idade e idosas ingressantes em um programa de atividades físicas em unidades de saúde. R bras Qual Vida 8(1): 85-100.

10. Rikli RE, Jones CJ (1999) Functional fitness normative scores for community-residing older adults, ages 60-94. Journal of Aging and Physical Activity 7: 162-181.

11. Fontoura A, Formentin C, Abech E (2011) Guia prático de avaliação física: uma abordagem didática, abrangente e atualizada.

12. Cardiologia SB (2010) Departamento de Hipertensão Arterial. VI Diretrizes brasileiras de hipertensão. Rev bras Hipertens 17(1): 1-64.

13. Fidelis LT, Patrizzi LJ, Walsh IAP (2013) Influência da prática de exercícios físicos sobre a flexibilidade, força muscular manual e mobilidade funcional em idosos. Rev Bras Geriatr Gerontol, Rio Janeiro, Brazil, 16(1): 109-116.

14. Cordeiro J, Castillo B, Freitas C, Gonçalves M (2014) Efeitos da atividade física na memória declarativa, capacidade funcional e qualidade de vida em idosos. Rev Bras Geriatr Gerontol, Rio Janeiro, Brazil, 17(3): 541-552.

15. Borges MRD, Moreira ÂK (2009) Influências da prática de atividades físicas na terceira idade : estudo comparativo dos níveis de autonomia para o desempenho nas AVDs e AIVDs entre idosos ativos fisicamente e idosos sedentários Milene Ribeiro Dias Borges Procedimentos me. Motriz 15(3): 562-573.

16. Dagios P, Vasconcellos C, Evangelista DHR (2015) Comparison between institutional and non-institutional participants introduction today, in brazil, we find an expressive population of elderly people. According to the demographic census of the Brazilian geographic institute. Interdiscipl Envelhec Study. pp. 469-484.

17. Martinez BP, Camelier FWR, Camelier AA (2014) Sarcopenia em idosos. Rev Pesqui em Fisioter 4(1): 62-70.

18. Ribeiro F, Gomes S, Teixeira F, Brochado G, Oliveira J (2009) Impact of regular practice of physical exercise on balance, functional mobility and risk of falls in institutionalized elderly people. TT-Impact of regular physical exercise participation in balance 9(1): 36-42.

19. Santos A dos, Júnior J (2017) Factors associated with poor quality of life in elderly women living in the municipality of Jequié-BA. Arq Sports Sciences 3(1): 11-15. 
Creative Commons Attribution 4.0 International License

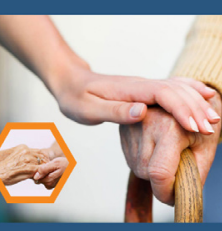

\section{Gerontology \& Geriatrics Studies}

Benefits of Publishing with us

- High-level peer review and editorial services

- Freely accessible online immediately upon publication

- Authors retain the copyright to their work

- Licensing it under a Creative Commons license

- Visibility through different online platforms 